\section{BMJ Open Respiratory Research}

\title{
Higher BMI is associated with higher expiratory airflow normalised for lung volume (FEF25-75/FVC) in COPD
}

Eric Abston, ${ }^{1}$ Alejandro Comellas, ${ }^{1,2}$ Robert Michael Reed, ${ }^{3}$ Victor Kim, ${ }^{4}$ Robert A Wise, ${ }^{5}$ Roy Brower, ${ }^{5}$ Spyridon Fortis, ${ }^{1,2}$ Reinhard Beichel, $, 1,6,7$ Surya Bhatt, ${ }^{8}$ Joseph Zabner, ${ }^{1,2}$ John Newell, ${ }^{7,9}$ Eric A Hoffman, ${ }^{1,6,7,9}$ Michael Eberlein ${ }^{1,2}$

To cite: Abston E, Comellas A, Reed RM, et al. Higher $\mathrm{BMI}$ is associated with higher expiratory airflow normalised for lung volume (FEF25-75/FVC) in COPD. BMJ Open Resp Res 2017;4:e000231. doi:10.1136/ bmjresp-2017-000231

Received 30 June 2017 Revised 4 September 2017

\section{CrossMark}

For numbered affiliations see end of article.

Correspondence to Dr Michael Eberlein; michael-eberlein@uiowa.edu

\section{ABSTRACT}

Introduction The obesity paradox in chronic obstructive pulmonary disease (COPD), whereby patients with higher body mass index (BMI) fare better, is poorly understood. Higher BMls are associated with lower lung volumes and greater lung elastic recoil, a key determinant of expiratory airflow. The forced expiratory flow (25-75) $\left(\mathrm{FEF}_{25-75}\right) /$ forced vital capacity (FVC) ratio reflects effort-independent expiratory airflow in the context of lung volume and could be modulated by BMI.

Methods We analysed data from the COPDGene study, an observational study of 10192 subjects, with at least a 10 pack-year smoking history. Data were limited to subjects with BMI $20-40 \mathrm{~kg} / \mathrm{m}^{2}$ ( $\left.\mathrm{n}=9222\right)$. Subjects were stratified according to forced expiratory volume in $1 \mathrm{~s}$ $\left(\mathrm{FEV}_{1}\right)$ (\%predicted)-quintiles. In regression analyses and Cox proportional hazard models, we analysed the association between $\mathrm{BMI}$, the $\mathrm{FEF}_{25-75} / \mathrm{FVC}$ ratio, the imaging phenotype, COPD exacerbations, hospitalisations and death.

Results There was no correlation between $\mathrm{BMI}$ and $\mathrm{FEV}_{1}$ (\%predicted). However, a higher $\mathrm{BMI}$ is correlated with a higher $\mathrm{FEF}_{25-75} / \mathrm{FVC}$ ratio. In CT scans, a higher BMI was associated with less emphysema and less air trapping. In risk-adjusted models, the quintile with the highest $\mathrm{FEF}_{25-75} /$ FVC ratio was associated with a $46 \%$ lower risk of COPD exacerbations (OR 0.54, $\mathrm{p}<0.001)$ and a $40 \%$ lower risk of death (HR 0.60, $p=0.02$ ), compared with the lowest quintile. BMI was not independently associated with these outcomes.

Conclusions A higher BMl is associated with lower lung volumes and higher expiratory airflows when normalised for lung volume, as quantified by the $\mathrm{FEF}_{25-75} / \mathrm{FVC}$ ratio. A higher $\mathrm{FEF}_{25-75} / \mathrm{FVC}$ ratio is associated with a lower risk of COPD exacerbations and death and might quantify functional aspects of the paradoxical effect of higher BMls on COPD.

\section{INTRODUCTION}

There exists a poorly understood obesity paradox in chronic obstructive pulmonary disease (COPD), ${ }^{1}$ where obese patients with COPD tend to fare better than non-obese patients with similar degree of airflow obstruction. $^{2}$ Observational studies show that over

\section{Key messages}

The obesity-paradox in COPD, whereby patients with higher body mass index (BMI) fare better, is poorly understood.

- In an ancillary study to COPDGene a higher BMI is associated with lower lung volumes and higher expiratory airflows when normalized for lung volume, as quantified by the $\mathrm{FEF}_{25-75} / \mathrm{FVC}$-ratio and a higher $\mathrm{FEF}_{25-75} / \mathrm{FVC}$-ratio is independently associated with a lower risk of COPD exacerbations and death.

- The $\mathrm{FEF}_{25-75} / \mathrm{FVC}$-ratio quantifies functional aspects of the paradoxical effect of BMI on COPD and further understanding of the physiological mechanism could lead to novel non-pharmacological therapies based on the analogies to chest wall strapping.

time obese patients with COPD experience lower mortality and fewer hospital admissions. ${ }^{34}$ Obesity has also been associated with lower mortality in patients with acute exacerbations. ${ }^{5}$

The mechanisms underlying this obesity paradox in COPD are unclear. Higher body mass index (BMI) in patients with COPD is associated with lower functional residual capacity (FRC)) and residual volume (RV), ${ }^{6}$ likely related to the mass effects of adipose tissue acting on the chest wall or abdomen. In addition to affecting the chest wall, higher BMI is associated with greater static lung elastic recoil, and in some studies with increased expiratory flow, ${ }^{8-10}$ as lung elastic recoil of the lung is the key determinant of maximal expiratory airflow.

The ratio of mid-vital capacity expiratory airflow (forced expiratory flow (25-75) $\left.\left(\mathrm{FEF}_{25-75}\right)\right)$ divided by the forced vital capacity (FVC) corresponds to effort-independent expiratory airflow adjusted for lung volume. We hypothesised that (1) a higher BMI is 


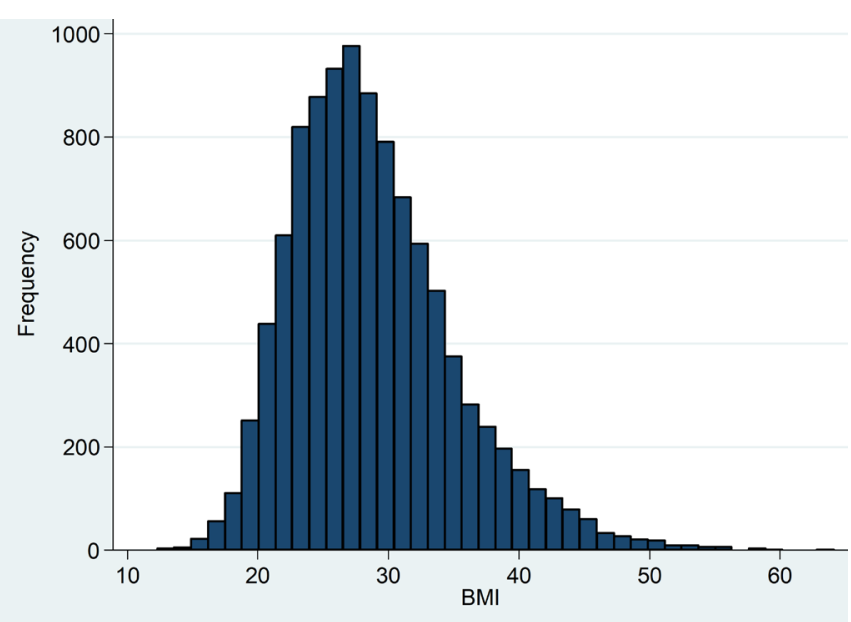

Figure 1 Histogram of the distribution of body mass index for the study population.

associated with a higher $\mathrm{FEF}_{25-75} / \mathrm{FVC}$ ratio and (2) that the $\mathrm{FEF}_{25-75} / \mathrm{FVC}$ ratio, as a possible functional correlate of the physiological effects of obesity, modulates the risk for COPD exacerbations and death.

\section{METHODS}

We evaluated data from the COPDGene study-an observational cohort study of 10192 participants across 21 centres in the USA (2008-2011). Participants were non-Hispanic Whites and African-Americans with at least a 10 pack-year smoking history. ${ }^{11}$ Each participant provided informed written consent. The COPDGene protocol has been previously described and is available at www.copdgene.org. ${ }^{11}$ Methods pertinent to the data analysed in this study are as follows: subjects completed spirometry according to the American Thoracic Society standards. ${ }^{11}$ High-resolution CT scans were performed at full inspiration and at end exhalation. Quantitative measures of emphysema were defined as the percentage of lung volume on the inspiratory CT with attenuation less than -950 Hounsfield units (HU) ${ }^{12}$ Gas trapping was defined as the percentage of lung volume on the expiratory CT with attenuation less than $-856 \mathrm{HU}^{12}$ The data were limited in this study to subjects with a BMI between 20 and $40 \mathrm{~kg} / \mathrm{m}^{2}(\mathrm{n}=9222)$ in order to limit the effects of spurious values and at physiological extremes of the BMI spectrum. Figure 1 shows a BMI histogram for the entire study population.

The study subjects were stratified according to forced expiratory volume in $1 \mathrm{~s}\left(\mathrm{FEV}_{1}\right)$ (\% predicted)-quintiles. The relationship between BMI, CT-imaging phenotype (CT volumetry, emphysema and air trapping), spirometry $\left(\mathrm{FEV}_{1}, \mathrm{FVC}\right.$ and $\left.\mathrm{FEV}_{1} / \mathrm{FVC}\right)$ and the $\mathrm{FEF}_{25-75} / \mathrm{FVC}$ ratio for the entire study population and within each $\mathrm{FEV}_{1}$ (\% predicted)-quintile was analysed by Spearman's rank correlation coefficients (Spearman's rho) and by using a fractional polynomial approach to evaluate for a possible non-linear association. We used logistic regression to evaluate the relationship between the $\mathrm{FEF}_{25-75} /$
FVC ratio, BMI and the occurrence of COPD exacerbations. The outcome variable, COPD exacerbation, was examined as a binary variable. A univariate analysis was performed to assess for variables that were associated with COPD exacerbation at a threshold of $\mathrm{p}=0.1$ as previously described, ${ }^{13}$ and those variables identified were then included in stepwise backward multivariate logistic models to adjust for confounders.

To evaluate the relationship between the $\mathrm{FEF}_{25-75} / \mathrm{FVC}$ ratio, BMI and the occurrence of COPD exacerbations in the study follow-up period, the COPDGene Longitudinal Follow-Up (LFU) dataset was utilised. ${ }^{14}$ The LFU dataset consists of telephone survey data obtained every 3-6 months after the initial study. Information on subjects including COPD exacerbations and hospitalisations was obtained. Follow-up COPDGene mortality data were analysed to evaluate the relationship between the $\mathrm{FEF}_{25-75} / \mathrm{FVC}$ ratio and mortality in the follow-up period. Cox proportional hazard models were used for the mortality analysis. We tested interactions between $\mathrm{FEF}_{25-}$ ${ }_{75} / \mathrm{FVC}$ ratio and $\mathrm{BMI}$, and the significance of differences between nested models was tested using the likelihood ratio test. Subjects with missing data were excluded from the respective analyses.

\section{RESULTS}

Patient demographics including metrics of disease severity, comorbid conditions, imaging parameters and spirometric values is shown in the table 1 in the online supplementary file 1, stratified by $\mathrm{FEV}_{1}$ (\% predicted)-quintiles. Comorbid conditions were more common in those with more severe COPD. BMI was not significantly different between $\mathrm{FEV}_{1}$-quintiles. All metrics of disease severity correlated with $\mathrm{FEV}_{1}$ (\% predicted)-quintiles.

No consistent relationship between $\mathrm{FEV}_{1}$ (\% predicted) and BMI were found when analysing the entire sample $(p=0.6)$, or within most $\mathrm{FEV}_{1}(\%$ predicted $)$-quintiles (figure 2A). However, a higher BMI was associated with lower FVC(\% predicted) (figure 2B). Consequently, a higher BMI was associated with higher $\mathrm{FEV}_{1} / \mathrm{FVC}$ ratios, both in the whole study population and in each $\mathrm{FEV}_{1}(\%$ predicted)-quintile $(\mathrm{p}<0.001)$ (figure $2 \mathrm{C})$. A higher BMI was associated with higher $\mathrm{FEF}_{25-75}$, both in the entire study population and in each quintile of $\mathrm{FEV}_{1}(\mathrm{p}=0.001)$ (figure $\left.3 \mathrm{~A}\right)$. There was a positive association between the $\mathrm{FEF}_{25-75} / \mathrm{FVC}$ ratio and BMI, both in the entire study population and in each quintile of $\mathrm{FEV}_{1}$ (\% predicted) $(\mathrm{p}=0.001)$ (figure $\left.3 \mathrm{~B}\right)$.

A higher BMI was associated with lower total lung capacity (TLC) (\% predicted) and functional residual capacity (FRC) (\%predicted) derived from CT volumetry (figure 4). A higher BMI correlated inversely with per cent emphysema $(\mathrm{p}<0.001)$ within most $\mathrm{FEV}_{1}$ (\% predicted)-quintile and for the entire study population (figure 5A). The slope of the line fitting this association was much steeper in the $\mathrm{FEV}_{1}(\%$ predicted $)$-quintile 
A)

B)

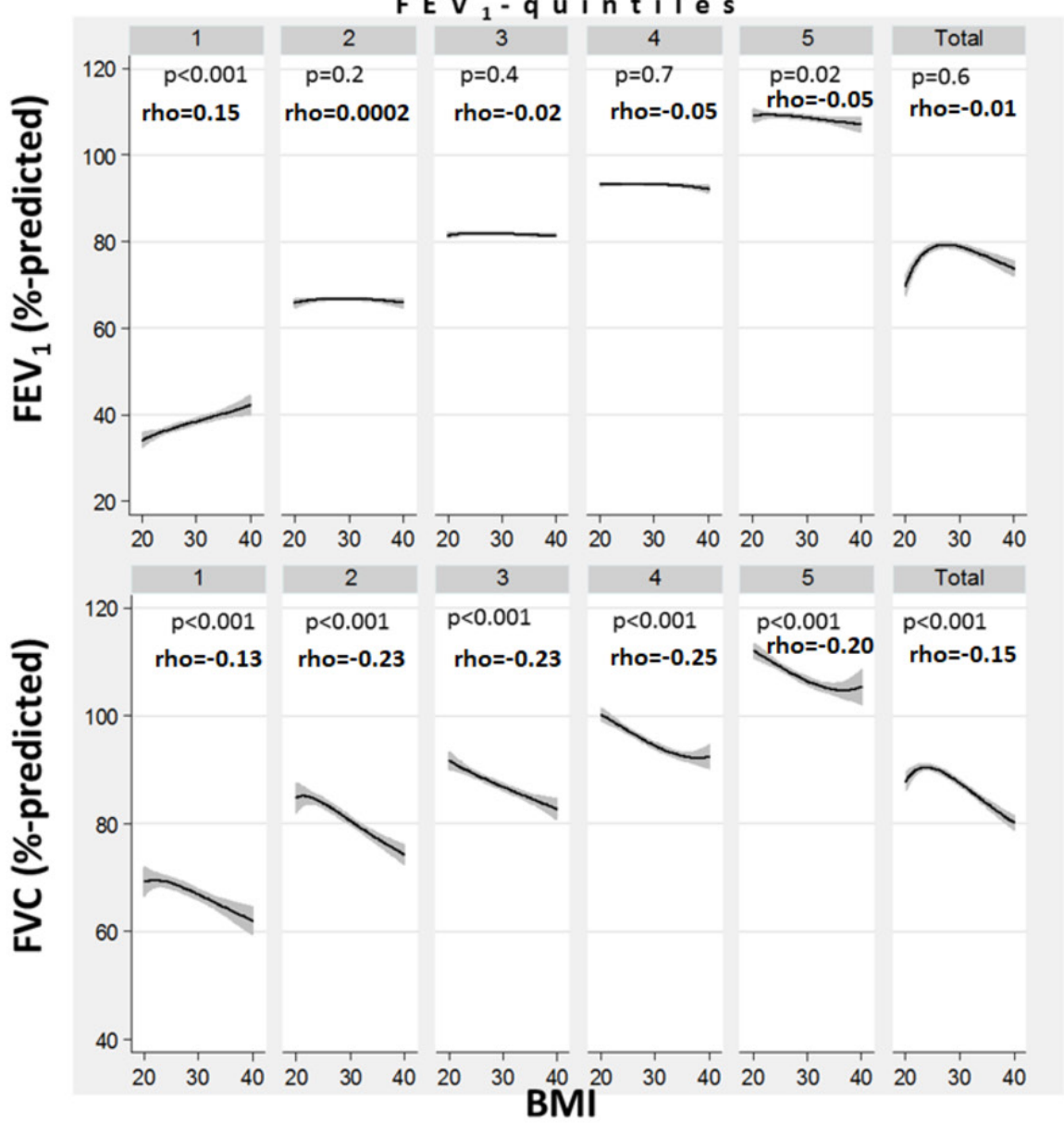

c)

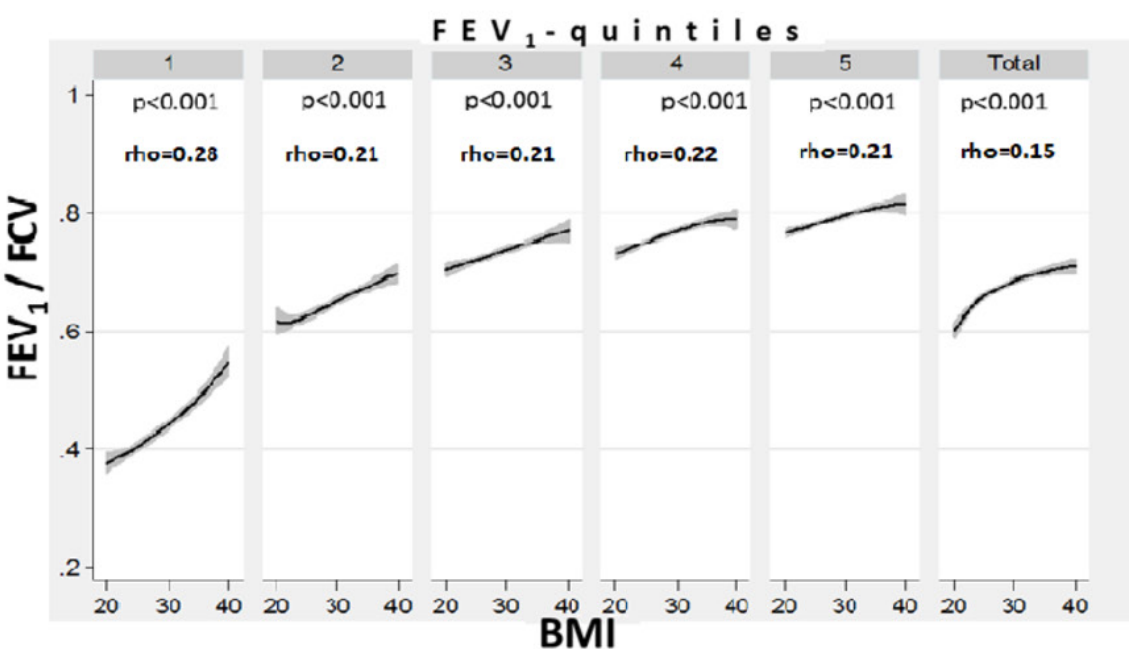

Figure 2 The relationship between body mass index (BMI) and per cent predicted forced expiratory volume in $1 \mathrm{~s}\left(\mathrm{FEV}_{1)}(\mathrm{A})\right.$ and per cent predicted forced vital capacity (FVC) (B) and the FEV $/ F V C$ ratio $(C)$, stratified by FEV ${ }_{1}$ quintiles and for the entire study population (BMI 20-40). Spearman's rank correlation coefficients (Spearman's rho) are shown and significance of the correlation is indicated by the corresponding $\mathrm{p}$ value.

with the lowest $\mathrm{FEV}_{1}$. This indicates that comparatively smaller differences in BMI correlated with much larger differences in emphysema in subjects with more severe disease than in quintiles with a more normal $\mathrm{FEV}_{1}$. A higher BMI correlated inversely with per cent air trapping $(\mathrm{p}<0.001)$ on expiratory CT scans within each
$\mathrm{FEV}_{1}(\%$ predicted)-quintile and for the entire study population (figure 5B). This reduction in air trapping with increasing BMI (from 20 to 40) was strongest in the $\mathrm{FEV}_{1}$ (\% predicted)-quintile with the lowest $\mathrm{FEV}_{1}$.

As the $\mathrm{FEF}_{25-75} / \mathrm{FVC}$ ratio could reflect the physiological impact of BMI on lung function we next evaluated 
A)

FEV - $_{3}$ - quintiles

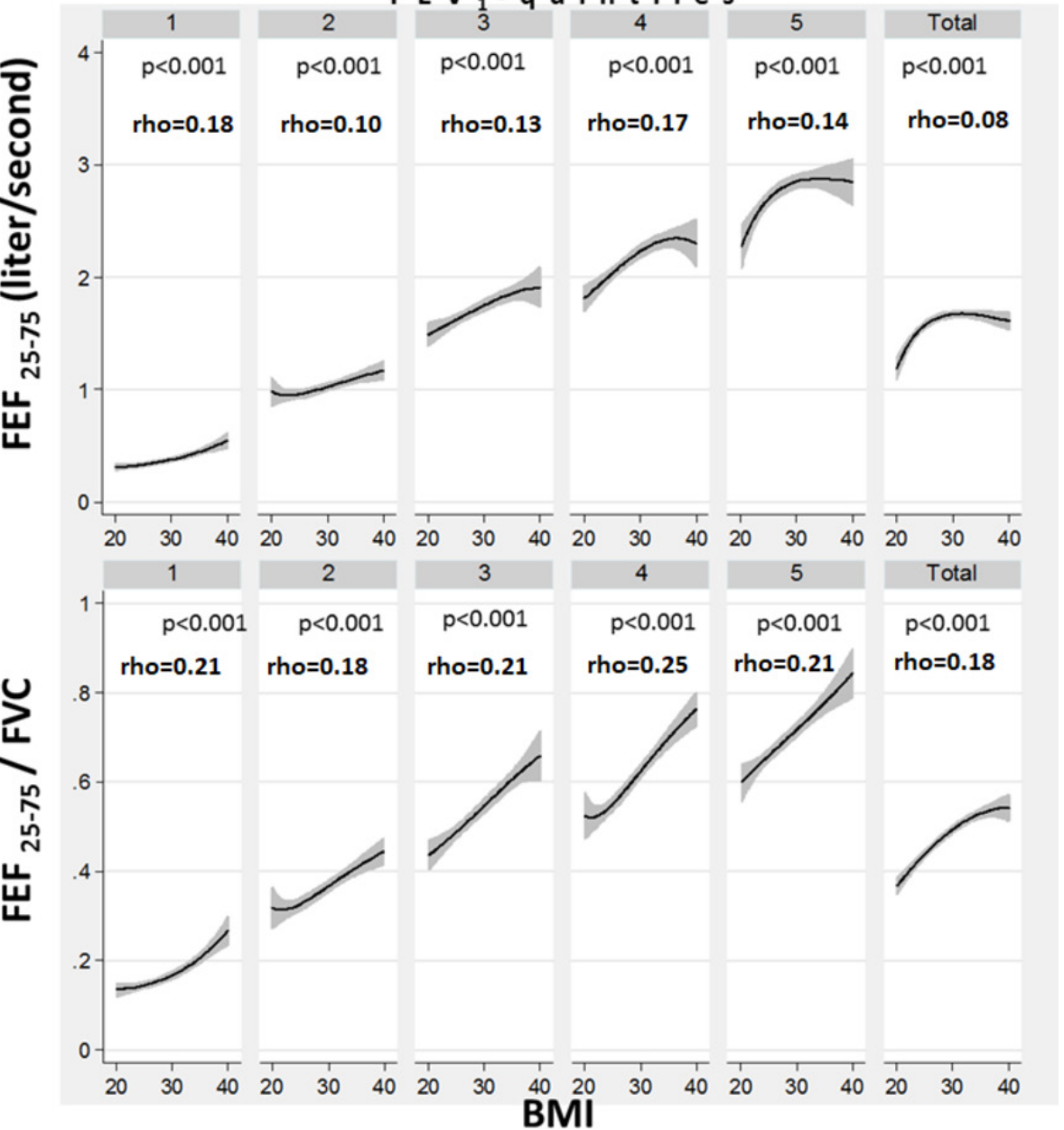

Figure 3 The relationship between body mass index $(\mathrm{BMI})$ and forced expiratory flow (25-75) $\left(\mathrm{FEF}_{25-75}\right)(\mathrm{A})$ and $\left(\mathrm{FEF}_{25-75}\right)$ divided by forced vital capacity (FVC) (B), stratified by forced expiratory volume in $1 \mathrm{~s}\left(\mathrm{FEV}_{1}\right)$ quintiles and for the entire study population (BMI 20-40). Spearman's rank correlation coefficients (Spearman's rho) are shown and significance of the correlation is indicated by the corresponding $p$ value.

the association between $\mathrm{FEF}_{25-75} / \mathrm{FVC}$ ratio, BMI and clinical outcomes in COPD. In unadjusted models a higher $\mathrm{FEF}_{25-75} / \mathrm{FVC}$ ratio was associated with a lower risk of self-reported COPD exacerbations at study entry and a lower occurrence of COPD exacerbations during the study follow-up period (table 1A). Furthermore, a higher $\mathrm{FEF}_{25-75} / \mathrm{FVC}$ ratio was associated with a lower risk of hospitalisations and a lower risk of death during the study follow-up period. When adjusting for BMI the $\mathrm{FEF}_{25-75} / \mathrm{FVC}$ ratio remained independently associated with the above clinical outcomes, whereas BMI itself did not remain consistently associated with these outcomes (table 1B). In comprehensive risk-adjusted models, a higher $\mathrm{FEF}_{25-75}$ /FVC ratio remained independently associated with a lower risk of COPD exacerbations, hospitalisation and mortality in the follow-up period.

\section{DISCUSSION}

In a large cohort of current and former smokers, we found that that $\mathrm{FEV}_{1}$ was largely unaffected by BMI. However, when analysing expiratory airflow in the context of the corresponding lung volumes via the $\mathrm{FEF}_{25-75} / \mathrm{FVC}$ ratio, a positive association between the $\mathrm{FEF}_{25-75} / \mathrm{FVC}$ ratio and BMI became evident. A higher $\mathrm{FEF}_{25-75} / \mathrm{FVC}$ ratio would either predict higher elastic recoil or greater small airway sizes for the same lung volume, and consistent with this we found higher BMI was associated with lesser emphysema and less air trapping. A higher $\mathrm{FEF}_{25-75} / \mathrm{FVC}$ ratio was associated with a lower risk of COPD exacerbations and death and might be a parameter that quantifies possible physiological effects associated with a higher BMI on COPD outcomes.

Classically, $\mathrm{FEV}_{1}$ has been used to quantify the disease severity in COPD. However, $\mathrm{FEV}_{1}$ was not modulated by obesity-related changes in lung function in previous studies, ${ }^{9}$ and similarly we did not find a consistent association between BMI and $\mathrm{FEV}_{1}$ in the current study. However, we found a positive correlation between BMI and $\mathrm{FEF}_{25-75}$ and an inverse relation between BMI and FVC. A misclassification of the severity of airflow obstruction by stratifying according to FEV1(\% predicted) could have affected the study results, as a reduction of 


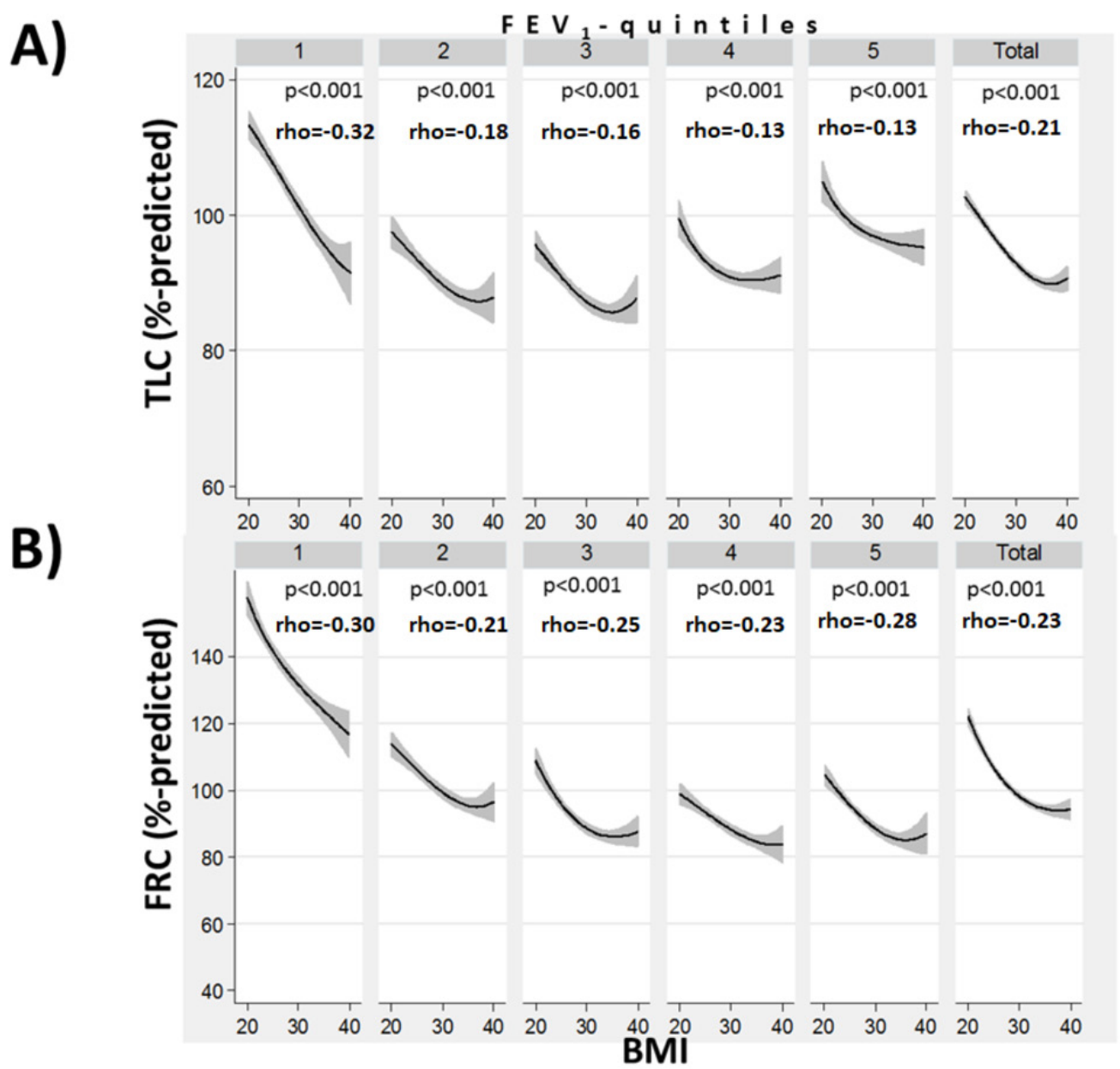

Figure 4 The relationship between body mass index (BMI) and total lung capacity (TLC) (A) and functional residual capacity $(F R C)(B)$, stratified by forced expiratory volume in $1 \mathrm{~s}\left(\mathrm{FEV}_{1}\right)$ quintiles and for the entire study population (BMI 20-40). Spearman's rank correlation coefficients (Spearman's rho) are shown and significance of the correlation is indicated by the corresponding $\mathrm{p}$-value.

lung volumes due to a restrictive process, like obesity, can add to the reduction in $\mathrm{FEV}_{1}$ from an obstructive disease. ${ }^{15}$ Thus, the reduced lung volumes from obesity might lead to an overestimation of the severity of the obstructive process. We performed a sensitivity analysis in which we adjusted the $\mathrm{FEV}_{1}$ (\% predicted) by the total lung capacity (TLC) (\% predicted), as derived from CT scans at full inspiration. We created $\mathrm{FEV}_{1}$ (\% predicted)${ }_{\text {adjusted }}=(\mathrm{FEV} 1$ (\% predicted) $/$ TLC (\% predicted) $)$. We then restratified subjects according to quintiles of $\mathrm{FEV}_{1}(\%$ pre-

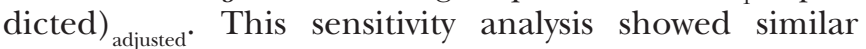
results (see figures 1 and 2 in the online supplementary file 1) and a higher BMI remained associated with a higher $\mathrm{FEF}_{25-75} / \mathrm{FVC}$ ratio, lesser emphysema and lesser air trapping.

Jere Mead developed a similar ratio $\left(\mathrm{FEF}_{25-75} / \mathrm{FVC}\right.$ multiplied by lung elastic recoil) to reflect the size of the airway structure in relation to the lung volume. ${ }^{16}$ He used this ratio to express the physiological variation in the geometry of the tracheobronchial tree and lung parenchyma due to different patterns of growth among both genders, which he termed dysanapsis. ${ }^{16}$ Thus, the higher $\mathrm{FEF}_{25-75} / \mathrm{FVC}$ ratio with increasing BMIs we found in this study would either predict higher elastic recoil or larger airway sizes for the same lung volume. A key finding of this study was that, as predicted by the association with a higher $\mathrm{FEF}_{25-75} / \mathrm{FVC}$ ratio, a higher BMI correlated inversely with per cent air trapping on expiratory CT scans (figure 5B). Air trapping is correlated with the closing volume of small airways and an isolated deflating effect of obesity should not affect the closing volume of small airways. Imaging studies in COPD have demonstrated that small conducting airways narrow and disappear before the onset of emphysematous disease. ${ }^{17}$ If it is correct that widespread narrowing and loss of smaller conducting airways precedes the onset of emphysematous destruction, then a possible beneficial effect of obesity on small airway function could reduce the risk for progression to emphysema. Similar to observations made in the Multiethnic Study of Atherosclerosis lung study, ${ }^{18}$ we found that a higher BMI was associated with less emphysema (figure 5). This could suggest that obesity modulates small airway function in COPD. 


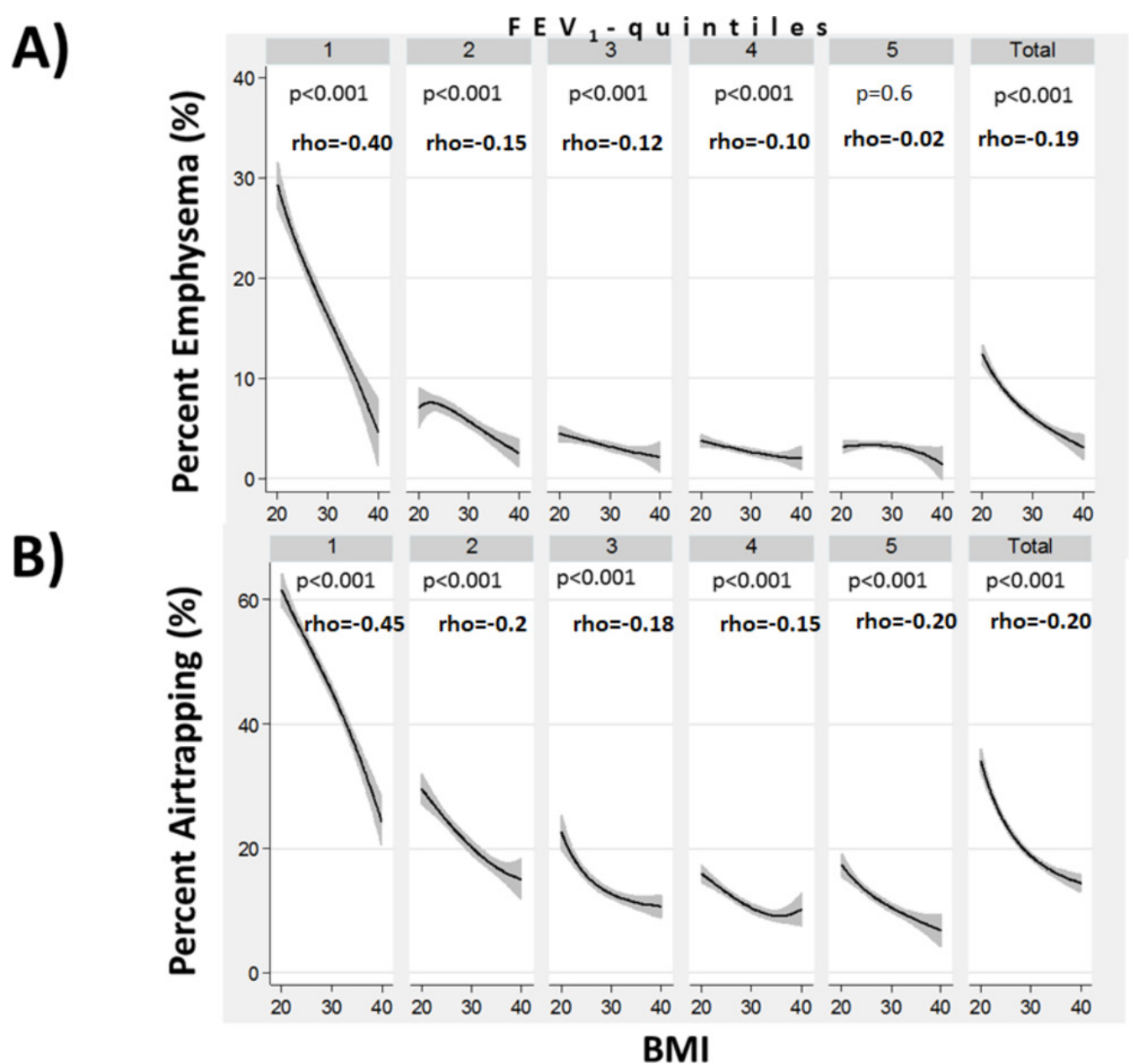

Figure 5 The relationship between body mass index (BMI) and per cent emphysema (A) and per cent air trapping (B), stratified by forced expiratory volume in $1 \mathrm{~s}\left(\mathrm{FEV}_{1}\right)$ quintiles and for the entire study population (BMI 20-40). Spearman's rank correlation coefficients (Spearman's rho) are shown and significance of the correlation is indicated by the corresponding $\mathrm{p}$ value.

The effects of obesity on pulmonary physiology have been carefully characterised both in healthy subjects and in those with COPD. ${ }^{9}$ The most prominent aspect of obesity-induced changes in the respiratory system is the reduction in expiratory reserve volume (ERV), followed by more modest reductions in other lung volumes. ${ }^{10}$ Obesity also reduces lung compliance and increases lung elastic recoil in several studies. ${ }^{8} 19$ There are analogies between the effects of obesity on the respiratory system and chest wall strapping (CWS) ${ }^{20-28}$ CWS is a technique to restrict chest and abdominal wall motion during respiration to force the lung to operate at lower lung volumes. ${ }^{20-28}$ CWS causes a decrease in lung volumes, an increase in expiratory flows and airway conductance, a decrease in lung compliance and an increase in lung elastic recoil. ${ }^{20-28}$ CWS reduces TLC by $\sim 35 \%$ with similar changes in vital capacity, FRC and similarly to obesity ERV is reduced the most by $50 \% .{ }^{20-28}$ Lung elastic recoil is increased by on average $180 \% .{ }^{20}$ CWS increases mid-vital capacity maximum expiratory flows to on average $150 \%$ of prestrapped rates. ${ }^{20}$ The increased lung elastic recoil from CWS could increase the radial traction on small airways via the interdependence between airways and parenchyma. ${ }^{20} 2930$ This increase radial traction could dilate small airways resulting in lower closing volumes and higher airway conductance..$^{20} 29$ Consistent with this possible mechanism, a study of normal subjects and in subjects with mild to moderate COPD showed that CWS increased the number of small airways detectable via an automated CT airway segmentation algorithm. ${ }^{31-33}$ Furthermore, transplanting significantly oversized donor lungs into a recipient with a smaller chest cavity is conceptually similar to CWS and was associated with higher mid-vital capacity expiratory airflows and higher $\mathrm{FEV}_{1} /$ FVC ratios. ${ }^{20} 34-37$ The $\mathrm{FEV}_{1} / \mathrm{FVC}$ ratio is conceptually also a 'dysanapsis ratio'. Similar to the $\mathrm{FEF}_{25-75} / \mathrm{FVC}$ ratio, the $\mathrm{FEV}_{1} / \mathrm{FVC}$ ratio varied with BMI (figure $2 \mathrm{C}$ ). Thus, a higher BMI could be associated with a normal $\mathrm{FEV}_{1} / \mathrm{FVC}$ ratio, even in the presence of obstructive airways disease. This may explain some of the observations regarding the 'GOLD-Unclassified Smokers' or 'preserved ratio impaired spirometry' phenotype that is characterised by a reduced $\mathrm{FEV}_{1}$ with a preserved $\mathrm{FEV}_{1} / \mathrm{FVC}$ ratio. ${ }^{38}$ Supporting this possibility, the 'GOLD-Unclassified 
Table 1: The association of FEV 25-75 / FVC ratio and BMI with COPD outcomes

\begin{tabular}{|c|c|c|c|c|c|c|}
\hline \multirow{2}{*}{$\begin{array}{l}\text { Parameter } \\
\text { Exacerbation* history }\end{array}$} & \multicolumn{3}{|c|}{ (A) Model 1, univariate } & \multicolumn{3}{|c|}{$\begin{array}{l}\text { (B) Model 2, multivariate adjusted (as } \\
\text { indicated in legend) }\end{array}$} \\
\hline & OR & $95 \%$ & p & OR $\neq$ & $95 \%$ & $\mathbf{p}$ \\
\hline $\begin{array}{l}\mathrm{FEF}_{25-75} / \mathrm{FVC} \text {-ratio } \\
\text { Quintile } 1 \text { versus } 5\end{array}$ & 0.11 & 0.09 to 0.14 & $<0.001$ & 0.55 & 0.21 to 1.40 & 0.2 \\
\hline $\begin{array}{l}\text { BMI } \\
\text { Quintile } 1 \text { versus } 5\end{array}$ & 1.28 & 1.10 to 1.50 & 0.002 & 1.08 & 0.65 to 1.79 & 0.7 \\
\hline Exacerbation* on follow up§ & OR & $95 \%$ & $\mathbf{p}$ & OR $\neq$ & $95 \%$ & $\mathbf{p}$ \\
\hline $\begin{array}{l}\mathrm{FEF}_{25-75} / \mathrm{FVC} \text { ratio } \\
\text { Quintile } 1 \text { versus } 5\end{array}$ & 0.28 & 0.25 to 0.32 & $<0.001$ & 0.54 & 0.39 to 0.73 & $<0.001$ \\
\hline $\begin{array}{l}\text { BMI } \\
\text { Quintile } 1 \text { versus } 5\end{array}$ & 1.1 & 0.97 to 1.25 & 0.14 & 1.13 & 0.892 to 1.39 & 0.2 \\
\hline Hospitalised $^{\star \star}$ & OR & $95 \%$ & p & ORף & $95 \%$ & $\mathbf{p}$ \\
\hline $\begin{array}{l}\mathrm{FEF}_{25-75} / \mathrm{FVC} \text { ratio } \\
\text { Quintile } 1 \text { versus } 5\end{array}$ & 0.09 & 0.07 to 0.21 & $<0.001$ & 0.41 & 0.27 to 0.63 & $<0.001$ \\
\hline $\begin{array}{l}\text { BMI } \\
\text { Quintile } 1 \text { versus } 5\end{array}$ & 0.97 & 0.79 to 1.19 & 0.8 & 1.30 & 0.94 to 1.79 & 0.1 \\
\hline Mortalityt† & HR & $95 \%$ & $\mathbf{p}$ & HRף & $95 \%$ & $\mathbf{p}$ \\
\hline $\begin{array}{l}\mathrm{FEF}_{25-75} / \mathrm{FVC} \text { ratio } \\
\text { Quintile } 1 \text { versus } 5\end{array}$ & 0.17 & 0.13 to 0.23 & $<0.001$ & 0.60 & 0.39 to 0.94 & 0.02 \\
\hline $\begin{array}{l}\text { BMI } \\
\text { Quintile } 1 \text { versus } 5\end{array}$ & 0.62 & 0.50 to 0.78 & $<0.001$ & 0.74 & 0.54 to 1.01 & 0.06 \\
\hline
\end{tabular}

${ }^{*}$ Exacerbation analysis is stratified according to exacerbation yes/no.

†Exacerbation data from first study visit.

$\ddagger$ Adjusted for: BMI, age at enrolment, history of severe exacerbations, chronic bronchitis, asthma, American Thoracic Society (ATS) packyear smoking, current smoking, fume exposure at work, gastro-oesophageal reflux disease, congestive heart failure, sleep apnoea, history of blood clots, high blood pressure, Modified Medical Research Council dyspnoea scale, St. George's Respiratory Questionnaire score, forced expiratory volume in $1 \mathrm{~s}$ (\% predicted) and 6 min walk distance.

$\S$ Exacerbation data from longitudinal follow-up data set.

TAdjusted for: BMI, pack-year smoking, current smoking, oxygen use, per cent emphysema and Body mass index, airflow Obstruction,

Dyspnoea and Exercise score.

${ }^{* *}$ Hospitalisation analysis is stratified according to yes/no.

††Complete mortality data were available for 7534 subjects.

$\mathrm{BMI}$, body mass index; $\mathrm{FEF}_{25-75}$, forced expiratory flow (25-75); FVC, forced vital capacity.

Smokers' phenotype was associated with increased BMIs. ${ }^{38}$

This study was limited in several aspects. Due to the cross-sectional nature of the study, we cannot determine a causal relationship between BMI and the imaging phenotype (lower TLC, FRC, less emphysema and air trapping). While the data is suggestive that obesity could have a CWS-like effect of increasing lung elastic recoil, we do not have measurements of lung elastic recoil or expiratory airflows at isovolume conditions. The $\mathrm{FEF}_{25-75} / \mathrm{FVC}$ ratio has been developed as a surrogate measure of airway size relative to lung size or lung dysanapsis. While FVC can be an appropriate surrogate of lung size in normal lungs, it can be reduced due to forced exhalation in subjects with COPD and emphysema, where FVC can be significantly lower than the slow vital capacity. In a sensitivity analysis, we have generated a 'dysanapsis' ratio that instead of FVC included TLC (derived from CT volumetry), as a measurement of lung size. There is close linear relationship between the $\mathrm{FEF}_{25-75} / \mathrm{FVC}$ ratio and the $\mathrm{FEF}_{25-75} /$ TLC ratio (Spearman's rho was $0.97, \mathrm{p}<0.0001$, see figure
3 in the online supplementary file 1). Also, BMI itself is an imperfect metric of adiposity, and different fat distribution patterns can result in varying respiratory effects with similar BMI. As gender can affect both fat distribution patterns and airway structure, we performed a sensitivity analysis stratified by gender, which showed similar results (see figure 4 in the online supplementary file 1 ). In this study, we limited the BMI to between 20 and 40, which excluded 970 subjects (approximately $10 \%$ of the study population). When we analysed the entire study cohort, the overall results were not different (see figures 5 and 6 in the online supplementary file 1).

There appears to be a plateau effect to the obesity-induced changes in lung function at the extremes of BMI. Mild to moderate obesity shares the greatest similarities with lung function changes observed with CWS, whereas extreme obesity, especially when FRC or ERV are reduced below certain thresholds can be associated with worsening lung function. ${ }^{39}$ In this study, the effect of BMI on $\mathrm{FEF}_{25-75}$ and $\mathrm{FEF}_{25-75} / \mathrm{FVC}$ seems to be more pronounced from BMI 20 to 30, then from BMI 30 to 40 (figure 3). 
Also, obesity is a complex chronic condition with varied patterns of fat depositions as well as many systemic and behavioural associations extending beyond mechanical effects of adipose tissue. ${ }^{940}$ Finally, even though multivariable modelling was used to account for possible confounding, it is understood that variables not available or missing variables in this data set may result in residual confounding.

In conclusion, increased BMI is associated with lower lung volumes, lesser emphysema and air trapping. The $\mathrm{FEF}_{25-75} / \mathrm{FVC}$ ratio, as a dysanapsis ratio, seems to quantify the physiological impact of obesity on the COPD phenotype and is independently associated with COPD exacerbations and mortality. BMI affects the COPD phenotype in a manner that has similarities to CWS, which could provide a possible mechanistic basis for aspects of the BMI paradox seen in COPD.

\section{Author affiliations}

${ }^{1}$ Department of Medicine, University of lowa, lowa City, lowa, USA

${ }^{2}$ Division of Pulmonary, Critical Care and Occupational Medicine, University of lowa, lowa City, lowa, USA

${ }^{3}$ Division of Pulmonary and Critical Care Medicine, University of Maryland

School of Medicine, Baltimore, Maryland, USA

${ }^{4}$ Division of Pulmonary and Critical Care Medicine, Temple University, School of Medicine, Philadelphia, Pennsylvania, USA

${ }^{5}$ Division of Pulmonary and Critical Care Medicine, Johns Hopkins University, Baltimore, Maryland, USA

${ }^{6}$ Department of Electrical and Computer Engineering, University of lowa, lowa City, Iowa, USA

${ }^{7}$ The lowa Institute for Biomedical Imaging, University of lowa, University of lowa, lowa City, Iowa, USA

${ }^{8}$ Division of Pulmonary, Allergy and Critical Care Medicine, University of Alabama, Birmingham, Alabama, USA

${ }^{9}$ Department of Radiology, University of lowa, lowa, USA

Collaborators Administrative Centre: James D Crapo, MD (PI); Edwin K Silverman, MD, PhD (PI); Barry J Make, MD; Elizabeth A Regan, MD, PhD. Genetic Analysis Centre: Terri Beaty, PhD; Ferdouse Begum, PhD; Robert Busch, MD; Peter J Castaldi, MD, MSc; Michael Cho, MD; Dawn L DeMeo, MD, MPH; Adel R Boueiz, MD; Marilyn G Foreman, MD, MS; Eitan Halper-Stromberg; Nadia N Hansel, MD, MPH; Megan E Hardin, MD; Lystra P Hayden, MD, MMSc; Craig P Hersh, MD, MPH; Jacqueline Hetmanski, MS, MPH; Brian D Hobbs, MD; John E Hokanson, MPH, PhD; Nan Laird, PhD; Christoph Lange, PhD; Sharon M Lutz, PhD; Merry-Lynn McDonald, PhD; Margaret M Parker, PhD; Dandi Qiao, PhD; Elizabeth A Regan, MD, PhD; Stephanie Santorico, PhD; Edwin K Silverman, MD, PhD; Emily S Wan, MD; Sungho Won. Imaging Centre: Mustafa Al Qaisi, MD; Harvey 0 Coxson, PhD; Teresa Gray; MeiLan K Han, MD, MS; Eric A Hoffman, PhD; Stephen Humphries, PhD; Francine L Jacobson, MD, MPH; Philip F Judy, PhD; Ella A Kazerooni, MD; Alex Kluiber; David A Lynch, MB; John D Newell, Jr, MD; Elizabeth A Regan, MD, PhD; James C Ross, PhD; Raul San Jose Estepar, PhD; Joyce Schroeder, MD; Jered Sieren; Douglas Stinson; Berend C Stoel, PhD; Juerg Tschirren, PhD; Edwin Van Beek, MD, PhD; Bram van Ginneken, PhD; Eva van Rikxoort, PhD; George Washko, MD; Carla G Wilson, MS. PFTQA Center, Salt Lake City, UT: Robert Jensen, $\mathrm{PhD}$. Data Coordinating Center and Biostatistics, National Jewish Health, Denver, CO: Douglas Everett, PhD; Jim Crooks, PhD; Camille Moore, PhD; Matt Strand, PhD; Carla G Wilson, MS. Epidemiology Core, University of Colorado Anschutz Medical Campus, Aurora, CO: John E Hokanson, MPH, PhD; John Hughes, PhD; Gregory Kinney, MPH, PhD; Sharon M Lutz, PhD; Katherine Pratte, MSPH; Kendra A Young, PhD. Ann Arbor VA: Jeffrey L Curtis, MD; Carlos H Martinez, MD, MPH; Perry G Pernicano, MD. Baylor College of Medicine, Houston, TX: Nicola Hanania, MD, MS; Philip Alapat, MD; Mustafa Atik, MD; Venkata Bandi, MD; Aladin Boriek, $\mathrm{PhD}$; Kalpatha Guntupalli, MD; Elizabeth Guy, MD; Arun Nachiappan, MD; Amit Parulekar, MD. Brighamand Women's Hospital, Boston, MA: Dawn L. DeMeo, MD, MPH; Craig Hersh, MD, MPH; Francine L Jacobson,MD, MPH; George Washko, MD. Columbia University, New York, NY: R Graham Barr, MD, DrPH; John Austin, MD; Belinda D'Souza, MD; Gregory D N Pearson, MD; Anna Rozenshtein, MD, MPH, FACR; Byron Thomashow, MD Duke University Medical Center, Durham, NC: Neil MacIntyre, Jr, MD; H Page McAdams, MD; Lacey Washington, MD. Health Partners
Research Institute, Minneapolis, MN: Charlene McEvoy, MD, MPH; Joseph Tashjian, MD. Johns Hopkins University, Baltimore, MD: Robert Wise, MD; Robert Brown, MD; Nadia N Hansel, MD, MPH; Karen Horton, MD; Allison Lambert, MD, MHS; Nirupama Putcha, MD, MHS. Los Angeles Biomedical Research Institute at Harbor UCLA Medical Center, Torrance, CA: Michael E DeBakey VAMC. Houston: Richard Casaburi, PhD, MD; Alessandra Adami, PhD; Matthew Budoff, MD; Hans Fischer, MD; Janos Porszasz, MD, PhD; Harry Rossiter, PhD; William Stringer, MD. TX: Amir Sharafkhaneh, MD, PhD; Charlie Lan, D0. Minneapolis VA: More house School of Medicine, Atlanta, GA: Marilyn G Foreman, MD, MS; Eugene Berkowitz, MD, PhD; Gloria Westney, MD, MS. National Jewish Health, Denver, C0: Russell Bowler, MD, PhD; David A Lynch, MB. Reliant Medical Group, Worcester, MA: Richard Rosiello, MD; David Pace, MD. Temple University, Philadelphia, PA: Gerard Criner, MD; David Ciccolella, MD; Francis Cordova, MD; Chandra Dass, MD; Gilbert D'Alonzo, DO; Parag Desai, MD; Michael Jacobs, PharmD; Steven Kelsen, MD, PhD; Victor Kim, MD; A James Mamary, MD; Nathaniel Marchetti, D0; Aditi Satti, MD; Kartik Shenoy, MD; RobertM Steiner, MD; Alex Swift, MD; Irene Swift, MD; Maria ElenaVegaSanchez, MD. Universityof Alabama, Birmingham, AL: Mark Dransfield, MD; William Bailey, MD; Surya Bhatt, MD; Anand lyer, MD; Hrudaya Nath, MD; J Michael Wells, MD. University of California, San Diego, CA: Joe Ramsdell, MD; Paul Friedman, MD; Xavier Soler, MD, PhD; AndrewYen, MD. Universityof lowa, lowa City, IA: Alejandro P Comellas, MD; John Newell, Jr, MD; Brad Thompson, MD. University of Michigan, Ann Arbor, MI: MeiLan K Han, MD, MS; Ella Kazerooni, MD; Carlos H. Martinez, MD, MPH. University of Minnesota, Minneapolis, MN: Joanne Billings, MD; Abbie Begnaud, MD; Tadashi Allen, MD. University of Pittsburgh, Pittsburgh, PA: Frank Sciurba, MD; Jessica Bon, MD; Divay Chandra, MD, MSc; CarlFuhrman, MD; Joel Weissfeld, MD, MPH. University of Texas Health Science Center at San Antonio, San Antonio, TX: Antonio Anzueto, MD; Sandra Adams, MD; Diego Maselli-Caceres, MD; Mario E Ruiz, MD.

Contributors Conception and design: EA, APC, ME. Analysis and interpretation: EA, APC, RMR, VK, RGB, SF, SPB, RRB, JDN, EAH and ME. Drafting the manuscript: EA and ME. Review of the manuscript for important intellectual content: EA, APC, RMR, VK, RAW, RGB, SF, SPB, RRB, JZ, JDN, EAH and ME.

Funding The project described was supported by award number R01HL089897 and award number R01HL089856 from the National Heart, Lung and Blood Institute.

\section{Competing interests None declared.}

Ethics approval Each study site received Institutional Review Board approval to participate in the study.

Provenance and peer review Not commissioned; externally peer reviewed.

Open Access This is an Open Access article distributed in accordance with the terms of the Creative Commons Attribution (CC BY 4.0) license, which permits others to distribute, remix, adapt and build upon this work, for commercial use, provided the original work is properly cited. See: http://creativecommons.org/ licenses/by/4.0/

C Article author(s) (or their employer(s) unless otherwise stated in the text of the article) 2017. All rights reserved. No commercial use is permitted unless otherwise expressly granted.

\section{REFERENCES}

1. Vandenbergh E, Van de Woestijne KP, Gyselen A. Weight changes in the terminal stages of chronic obstructive pulmonary disease. Relation to respiratory function and prognosis. Am Rev Respir Dis 1967:95:556-66.

2. Pinto LM, Alghamdi M, Benedetti $A$, et al. Derivation and validation of clinical phenotypes for COPD: a systematic review. Respir Res 2015;16:50.

3. Cao C, Wang R, Wang J, et al. Body mass index and mortality in chronic obstructive pulmonary disease: a meta-analysis. PLoS One 2012;7:e43892.

4. Landbo C, Prescott E, Lange P, et al. Prognostic value of nutritional status in chronic obstructive pulmonary disease. Am J Respir Crit Care Med 1999;160:1856-61.

5. Lainscak M, von Haehling S, Doehner W, et al. Body mass index and prognosis in patients hospitalized with acute exacerbation of chronic obstructive pulmonary disease. J Cachexia Sarcopenia Muscle 2011:2:81-6.

6. O'Donnell DE, Deesomchok A, Lam YM, et al. Effects of BMI on static lung volumes in patients with airway obstruction. Chest 2011:140:461-8.

7. Salome CM, King GG, Berend N. Physiology of obesity and effects on lung function. J Appl Physiol 2010;108:206-11. 
8. Ora J, Laveneziana P, Wadell K, et al. Effect of obesity on respiratory mechanics during rest and exercise in COPD. J Appl Physiol 2011:111:10-19.

9. O'Donnell DE, Ciavaglia CE, Neder JA. When obesity and chronic obstructive pulmonary disease collide. Physiological and clinical consequences. Ann Am Thorac Soc 2014;11:635-44.

10. Ora J, Laveneziana P, Ofir D, et al. Combined effects of obesity and chronic obstructive pulmonary disease on dyspnea and exercise tolerance. Am J Respir Crit Care Med 2009;180:964-71.

11. Regan EA, Hokanson JE, Murphy JR, et al. Genetic epidemiology of COPD (COPDGene) study design. COPD 2010;7:32-43.

12. Hersh CP, Washko GR, Estépar RS, et al. Paired inspiratoryexpiratory chest CT scans to assess for small airways disease in COPD. Respir Res 2013;14:42.

13. Wells JM, Washko GR, Han MK, et al. Pulmonary arterial enlargement and acute exacerbations of COPD. N Engl J Med 2012;367:913-21.

14. Stewart JI, Moyle S, Criner GJ, et al. Automated telecommunication to obtain longitudinal follow-up in a multicenter cross-sectional COPD study. COPD 2012;9:466-72.

15. Gardner ZS, Ruppel GL, Kaminsky DA. Grading the severity of obstruction in mixed obstructive-restrictive lung disease. Chest 2011;140:598-603.

16. Mead J. Dysanapsis in normal lungs assessed by the relationship between maximal flow, static recoil, and vital capacity. Am Rev Respir Dis 1980;121:339-42.

17. McDonough JE, Yuan R, Suzuki M, et al. Small-airway obstruction and emphysema in chronic obstructive pulmonary disease. $N$ Engl $J$ Med 2011;365:1567-75.

18. Barr RG, Ahmed FS, Carr JJ, et al. Subclinical atherosclerosis, airflow obstruction and emphysema: the MESA Lung Study. Eur Respir J 2012;39:846-54.

19. Pelosi P, Croci M, Ravagnan I, et al. Total respiratory system, lung, and chest wall mechanics in sedated-paralyzed postoperative morbidly obese patients. Chest 1996;109:144-51.

20. Eberlein M, Schmidt GA, Brower RG. Chest wall strapping. An old physiology experiment with new relevance to small airways diseases. Ann Am Thorac Soc 2014;11:1258-66.

21. Caro CG, Butler J, Dubois AB. Some effects of restriction of chest cage expansion on pulmonary function in man: an experimental study. J Clin Invest 1960;39:573-83.

22. Bradley CA, Anthonisen NR. Rib cage and abdominal restrictions have different effects on lung mechanics. J Appl Physiol Respir Environ Exerc Physiol 1980;49:946-52.

23. Butler J, Caro CG, Alcala R, et al. Physiological factors affecting airway resistance in normal subjects and in patients with obstructive respiratory disease. J Clin Invest 1960;39:584-91.
24. Sybrecht GW, Garrett L, Anthonisen NR. Effect of chest strapping on regional lung function. $J$ Appl Physiol 1975;39:707-13.

25. Douglas NJ, Drummond GB, Sudlow MF. Breathing at low lung volumes and chest strapping: a comparison of lung mechanics. $J$ Appl Physiol Respir Environ Exerc Physiol 1981;50:650-7.

26. Klineberg PL, Rehder K, Hyatt RE. Pulmonary mechanics and gas exchange in seated normal men with chest restriction. $J$ Appl Physiol Respir Environ Exerc Physiol 1981;51:26-32.

27. Stubbs SE, Hyatt RE. Effect of increased lung recoil pressure on maximal expiratory flow in normal subjects. J Appl Physiol 1972;32:325-31.

28. Scheidt M, Hyatt RE, Rehder K. Effects of rib cage or abdominal restriction on lung mechanics. J Appl Physiol Respir Environ Exerc Physiol 1981;51:1115-21.

29. Paré PD, Mitzner W. Airway-parenchymal interdependence. Compr Physiol 2012;2:1921-35.

30. Nakamura M, Sasaki H, Takishima T. Effect of lung surface tension on bronchial collapsibility in excised dog lungs. J Appl Physiol Respir Environ Exerc Physiol 1979;47:692-700.

31. Taher $\mathrm{H}$, Bauer $\mathrm{C}$, Winnike $\mathrm{H}$, et al. Chest wall strapping induces small airway dilation and enhances expiratory airflow. Am Respi Crit Care Med 2015;191:A1206.

32. Taher H, Winnike H, Zabner J, et al. Chest wall strapping improves expiratory airflow and reduces air trapping and hyperinflation in mild to moderate COPD. Am J Respi Crit Care Med 2016;193:A6865.

33. Bauer C, Eberlein M, Beichel RR. Graph-based airway tree reconstruction from chest CT scans: evaluation of different features on five cohorts. IEEE Trans Med Imaging 2015;34:1063-76.

34. Eberlein M, Permutt S, Brown $\mathrm{RH}$, et al. Supranormal expiratory airflow after bilateral lung transplantation is associated with improved survival. Am J Respir Crit Care Med 2011;183:79-87.

35. Eberlein M, Permutt S, Chahla MF, et al. Lung size mismatch in bilateral lung transplantation is associated with allograft function and bronchiolitis obliterans syndrome. Chest 2012;141:451-60.

36. Eberlein M, Reed RM, Maidaa M, et al. Donor-recipient size matching and survival after lung transplantation. A cohort study. Ann Am Thorac Soc 2013;10:418-25.

37. Eberlein M, Reed RM. Donor to recipient sizing in thoracic organ transplantation. World J Transplant 2016;6:155-64.

38. Wan ES, Hokanson JE, Murphy JR, et al. Clinical and radiographic predictors of GOLD-unclassified smokers in the COPDGene study. Am J Respir Crit Care Med 2011;184:57-63.

39. Pellegrino R, Gobbi A, Antonelli A, et al. Ventilation heterogeneity in obesity. J Appl Physiol 2014;116:1175-81.

40. Adams JP, Murphy PG. Obesity in anaesthesia and intensive care. $\mathrm{Br}$ $J$ Anaesth 2000;85:91-108. 